\title{
SINDICALISMO NO RAMO DE TELECOMUNICAÇÕES dO PARANÁ: A ATUAÇÃO DO SINTTEL FRENTE À SERCOMTEL NAS DÉCADAS DE 1980 E 1990
}

\section{Givaldo Alves da Silva ${ }^{1}$}

\begin{abstract}
RESUMO
No presente trabalho são apresentados dados e análises acerca da atuação do Sindicato dos Telefônicos do Paraná (SINTTEL) em relação à Sercomtel, empresa de telefonia que presta serviços na cidade de Londrina. A construção do texto foi possível a partir de investigação de campo, pesquisa documental e pesquisa bibliográfica. Os resultados apontam que as ações do sindicato em relação à empresa têm especificidades em relação à política de confronto adotada com as demais empresas do ramo de telecomunicações e que, tais estratégias resultaram em prejuízos para a categoria, apesar de terem sido importantes para a manutenção da Sercomtel como empresa pública.
\end{abstract}

Palavras-chave: Neoliberalismo. Reestruturação produtiva. Sindicalismo. Sercomtel.

\footnotetext{
${ }^{1}$ Professor da FAFIPA - Faculdade Estadual de Educação Ciências e Letras de Paranavaí. End. eletrônico: givaldo33@yahoo.com.br
} 


\title{
Telecommunications unionism in Paraná: SINTTEL'S STRATEGY IN RELATION TO SERCOMTEL IN THE 1980s AND 1990s
}

\begin{abstract}
In this paper we present data and analysis on the strategy of the Telephone Workers' Union of Paraná (SINTTEL) relative to Sercomtel, the telephone company that provides service in the city of Londrina. The construction of this study is based on field research, analysis of documents and bibliographic research. The results show that the union's behavior in this case had certain distinguishing characteristics in relation to the policy of confrontation adopted in other telecommunications firms and that its strategies were damaging to workers, despite the fact that they played an important role in maintaining Sercomtel as a public enterprise.
\end{abstract}

Keywords: Neoliberalism. Productive restructuring. Unionism. Sercomtel.

\section{INTRODUÇÃO}

s transformações pelas quais passou o Brasil em função das políticas
neoliberaise todas asconseqüências do impacto doprocesso demundialização
do capital e sua reestruturação produtiva tiveram várias conseqüências aos trabalhadores e às suas formas de atuar politicamente.

0 presente texto mostra como esse conjunto de transformações atingiu os trabalhadores de uma empresa pública de telefonia que atua no município de Londrina, no Paraná.

A Sercomtel é a única empresa de telefonia brasileira que resistiu ao processo de privatização e continua pertencendo majoritariamente ao município de Londrina. Para que continuasse pública, várias batalhas políticas foram travadas envolvendo diversos atores sociais, dentre eles administradores municipais, diretores da empresa, sociedade civil e, em grande medida, os próprios trabalhadores da empresa por via do sindicato que os representa, o SINTTEL-PR.

Durante toda a década de 1990, o SINTTEL orientou suas ações no sentido de evitar o processo de privatização da Sercomtel, orientando os trabalhadores, negociando, enfrentando a administração municipal e, por muitas vezes, envolvendo a sociedade civil na luta pela preservação da empresa. 


\section{TransformaÇões NO MUNDO DO TRABALHO E A LUTA DOS TELEFÔNICOS BRASILEIROS}

A adesão da classe trabalhadora, após a segunda guerra, às políticas de confronto e pacto institucional revelaram seus limites e fragilidades com as mudanças ocorridas no interior do modo de produção capitalista a partir dos anos 1970 (OLIVEIRA,1994). 0 recuo em relação à luta de classes ocorrida internacionalmente resultando na fragmentação das políticas de classe com tendências a fragmentações cada vez maiores até a prática do sindicalismo de empresa, revelou que a ofensiva do capital em sua fase de mundialização logrou sucesso frente à fragmentação e institucionalização da classe trabalhadora, iniciada com o pacto fordista (BIHR, 1998), o complexo de reestruturação produtiva, cujo modelo de acumulação flexível traz em seu bojo inovações tecnológicas, terceirizações e os programas de qualidade total (ALVES, 2000), resultaram em uma dura ofensiva às políticas fragmentárias e institucionais da classe trabalhadora.

A introdução de novas tecnologias que transformaram a base tecnológica das empresas e a crise do próprio sistema do capital - revelada pelo baixo crescimento econômico da maioria das economias capitalistas a partir da década de 1970 - forçaram a flexibilização da capacidade das empresas, o que, aliado com as políticas de terceirização e as novas técnicas de gerenciamento do trabalho, previstas nos programas de qualidade total, resultaram no crescente quadro de desemprego estrutural e na precarização das condições de trabalho que atingem grande parte da classe trabalhadora em todo o mundo (SILVA; SANTOS, 2006).

As estratégias adotadas pela classe trabalhadora na maioria dos países, e também no Brasil, em resposta à nova ofensiva do capital sob o contexto de sua mundialização, mais uma vez traduziram-se em limites e principalmente na perda de conquistas históricas da classe, o que significou um quadro de recuo da classe na luta contra o capital (SANTOS, 2001).

Nesse sentido, a trajetória dos telefônicos brasileiros na década de 1990 percorreu um caminho similar ao da maior parte da classe trabalhadora. Iniciaram a década de 1990 praticando as políticas de confronto que haviam se revelado eficientes no contexto político-econômico dominado pelas práticas keynesianas, entretanto, não conseguiram formular uma estratégia que pudesse fazer frente às mudanças econômicas de cunho neoliberal que seriam adotadas pelos sucessivos governos brasileiros a partir daquela década. 
A privatização do setor revelou-se um eficiente instrumento do capital no sentido de desarticular a forte organização nacional que os telefônicos haviam construído a partir de meados da década de 1980. A incapacidade da categoria de promover negociações nacionais, a aquisição das diferentes empresas por grupos financeiros distintos e a fragilização do poder político dos trabalhadores devido ao quadro de reestruturação minaram a capacidade de oposição dos telefônicos.

Diante da privatização do setor, os representantes dos telefônicos, ainda que tentassem, não foram capazes de organizar a categoria e fazer frente às ofensivas das empresas que vieram no sentido de precarizar suas condições de trabalho. 0 grande número de demissões e o crescente desemprego em todo o país serviram de motivação para que os trabalhadores se engajassem nos projetos das empresas em detrimento dos apelos de seus representantes no sentido de continuarem com a política de confronto.

No Paraná, a mudança de postura da categoria dos telefônicos pode ser claramente percebida em dois momentos: o primeiro, no ano de 1999, quando a chapa MOT venceu as eleições do Sinttel, derrotando a Biqueira de Aço, que se reelegia desde 1987 e, o segundo, em 2002 com a chapa Novos Rumos que rompeu definitivamente com a CUT e com a FITTEL, voltando a afiliar o sindicato à FENATTEL.

\section{ESTRATÉGIAS DE LUTA DO SINTTEL-PR NAS DÉCADAS DE 1980 E 1990 DO SÉCULO XX}

Com o intuito de situar o leitor, é importante que se diga que o SINTTELPR tem uma estrutura administrativa que se divide em 5 coordenações: Curitiba, Londrina, Ponta Grossa, Guarapuava e Cascavel. Devido às especificidades da relação do sindicato com a administração do município, a coordenação de Londrina sempre teve uma pauta diferenciada em relação às demais coordenações do Estado.

Durante 20 anos, o SINTTEL-PR foi dirigido por gestões atreladas às empresas de telecomunicações do Estado e só em 1987, a chapa Biqueira de Aço, assumiu a direção do sindicato.

A prática de atrelamento às empresas, a partir de então foi substituída pelas políticas de enfrentamento que começavam a se despontar em nível nacional depois de terem sido iniciadas pelo SINTTEL-MG (CUNHA, 2002; LIMA, 1997). 
A atuação do SINTTEL-PR durante as sucessivas gestões da chapa Biqueira de Aço esteve em sintonia com as deliberações da Federação Interestadual dos Trabalhadores Telefônicos - FITTEL, que nasceu com a proposta de construir um sindicalismo mais independente do Estado, balizando-se nas políticas de confronto defendidas à época pela Central Única dos Trabalhadores - CUT.

Desde o início das práticas de confronto os telefônicos passaram a ampliar sobremaneira a capacidade de barganha junto à empresa, conseguindo conquistar uma série de direitos e benefícios (SILVA, 2003).

Entretanto as práticas de confronto lograram sucesso somente até o ano de 1997. Com a privatização do Sistema Telebrás no ano de 1998 e todas as conseqüências do regime de mercado que é inaugurado a partir de então, acabam atingindo a Sercomtel e pressionando a mudança nas práticas de confronto.

0 acordo coletivo de 1998, o primeiro que os telefônicos fizeram em nível nacional com a iniciativa privada mostrou os limites da organização da categoria.

A implantação dos programas de demissão voluntária, os intensos processos de terceirização e a descentralização das negociações que antes ocorriam em boa parte entre a FITTEL e o Sistema Telebrás constituíram-se em golpes importantes na organização da categoria (SILVA, 2003a).

0 temor do desemprego e o endurecimento dos novos empregadores nas mesas de negociação acabaram resultando no recuo da categoria nas políticas de enfrentamento. A conseqüência imediata da nova configuração tomada pelo setor após a privatização foi a perda de vários benefícios históricos conquistados a duras penas durante as décadas de 1980 e 1990 (SILVA, 2003, p. 136-138).

Outra conseqüência das mudanças que tiveram grande importância para a categoria foi a eleição, em 1999, da chapa MOT que assumiu a direção do SINTELPR após 12 anos consecutivos de gestão da chapa Biqueira de Aço.

A nova direção inaugurou uma nova política de abrandamento no discurso e na prática do sindicato em relação às empresas. Nas palavras de Araújo, a gestão MOT

Correspondeu a uma mudança política no sindicalismo cutista e na agenda sindical, provocada pela privatização, modernização tecnológica e aumento da terceirização no ramo das telecomunicações. Pode-se classificar essa mudança como o abandono de uma postura de confronto para outra mais propensa à negociação, marcando uma conjuntura de reversão no movimento sindical, propiciada tanto por razões estruturais, quanto por motivos institucionais nas soluções de enfrentamento (ARAÚJO, 2000, p. 7). 
Diante das novas dificuldades enfrentadas pela categoria demissões, terceirizações, entre outras, o sindicato passou a desenvolver políticas de concertação social para a categoria. Um exemplo disso é o Projeto Solidariedade que se constitui no convênio do sindicato com empresas comerciais objetivando a redução do preço de mercadorias para seus associados (VIVAVOZ, n. 4, dez. 99, p. 2).

Outro exemplo foi a parceria do sindicato com a Universidade Federal do Paraná no sentido de incentivar a criação da Coopertel, a primeira cooperativa de prestação de serviços dos telefônicos do Paraná, fundada em 2000. A cooperativa é composta por trabalhadores demitidos das empresas de telecomunicações e tem, entre outros, o objetivo de concorrer com as empreiteiras na terceirização dos serviços da empresas de telefonia.

A gestão MOT, assim como as empresas de telecomunicações, promoveu uma reestruturação no SINTTEL-PR e em função disso, em março de 2000 contabilizou-se que desde a posse daquela gestão, ocorrida no início daquele ano, o escritório do sindicato em Curitiba havia reduzido de 24 para 14 o número de empregados (VIVAVOZ, n. 6, mar. 2000, p. 4).

A referida reestruturação, conforme alegação da própria diretoria foi necessária devido à queda dos valores das contribuições dos trabalhadores ao sindicato em decorrência das demissões e das reduções salariais advindas dos cortes de benefícios da categoria.

Logo após a privatização das empresas de telefonia do Estado, a direção do SINTTEL-PR passou a ter dificuldade de acesso aos locais de trabalho. Araújo resume as dificuldades enfrentadas pelo sindicato em relação às negociações com as empresas privatizadas:

A ação sindical passou a ser menos agressiva, limitando-se a uma política de abonos, cuja troca procura compensar alguns direitos dos trabalhadores que foram eliminados. [...] A tensão no ambiente de trabalho agravou-se pela inexistência de reajuste salarial no primeiro ano pós-privatização, a instabilidade no emprego, a crescente precarização das relações de trabalho, 0 aumento da carga de trabalho, a desconfiança das equipes, o temor das demissões, a concorrência no mercado, as alterações de funções, mediante a aplicação de um plano de cargos e salários submetido a ajustes constantes (ARAÚJ0, 2000, p. 5).

As mudanças no interior das empresas, dentre elas o medo do desemprego e o envolvimento dos trabalhadores com os projetos empresariais, tiveram reflexo na 
representação sindical da categoria no Paraná. Assim, em abril de 2002, rompeuse uma história de 14 anos de vinculação do sindicato às políticas cutistas.

Naquele ano, a chapa Novos Rumos apoiada pela FENATTEL Federação Nacional dos Trabalhadores Telefônicos venceu as eleições, rompendo definitivamente com as políticas cutistas, efetuando, inclusive, a desfiliação do sindicato àquela central e à FITTEL ${ }^{2}$.

A mudança que a Novos Rumos propõe pode ser observada na entrevista concedida por um dos diretores ao boletim do sindicato:

Estamos buscando novos benefícios para os sindicalizados, inclusive estamos vendo a possibilidade de montarmos um consultório odontológico para podermos oferecer um tratamento de qualidade e com o menor custo possível. Também queremos construir uma área de lazer na praia de Guaratuba e outra em Londrina. Sabemos que temos um grande desafio com as empresas que estão vindo para o Paraná. Além das lutas de sempre por melhores salários e condições de trabalho (VIVAVOZ, jun. 2002).

A Novos Rumos, na prática, tem, aprofundado as políticas propositivas da categoria junto às empresas e procurado resolver o problema da reversão dos baixos índices de sindicalização - decorrentes da descrença da categoria no poder de barganha do sindicato - por meio de políticas assistencialistas como a promoção dos convênios junto ao comércio e a criação de estruturas de promoção do lazer e da saúde citadas acima.

Traduzindo as dificuldades encontradas pelo sindicato e analisando sua atuação em relação à outra empresa de telefonia do Estado, Araújo (2000, p. 6), diz:

0 Sinttel tem experimentado uma trajetória política pontuada por mudanças em questões relativas à sua sobrevivência e à dos trabalhadores: 0 desencadear de uma campanha pública contra o processo de privatização (da Telepar); a perda da condição de negociação com uma empresa estatal em acordos controláveis; conseqüências dos processos de reestruturação; enfrentamento de situação de dispensa de trabalhadores e planos de demissão estimulada pela empresa; reorganização do trabalho e formas contratuais alteradas; defesa dos empregos e das conquistas dos trabalhadores; tentativas de qualificação dos trabalhadores; desarticulação do mercado de trabalho e dessindicalização da categoria. Com as demissões a ação sindical dos telefônicos passou da proteção representativa à defesa do trabalhador junto ao Ministério

\footnotetext{
${ }^{2}$ A FENATTEL é primeira Federação criada para representar os telefônicos, ainda no período ditatorial. Os partidários do novo sindicalismo acusavam a FENATTEL de "peleguismo".
} 
Público; do acompanhamento quanto à capacitação do trabalhador à livre concorrência e atravessamento das empreiteiras no mercado; da jurisdição ao trabalho formal às experiências de cooperativas de trabalhadores; de uma situação relativamente estável de negociação com empresa estatal à falta de transparência na política salarial das empresas de telecomunicações.

A diferença da conjuntura e da postura adotada pela nova direção do sindicato pode ser percebida até mesmo pelo conteúdo do boletim informativo da categoria. Se antes, principalmente nas gestões Biqueira de Aço, a conjuntura político-econômica nacional e internacional ocupava boa parte das edições, juntamente com denúncias às empresas e até mesmo a determinados diretores e encarregados, as matérias do VivaVoz (boletim publicado pela Novos Rumos) resumem-se basicamente às questões pertinentes à base territorial do sindicato e, conseqüentemente, internas à categoria. Outras colunas como Saúde, Aposentados, Jurídico, Informática e informativos de festividades da categoria complementam as edições.

\section{SINTTEL X SERCOMTEL: CONFRONTO E PROPOSIÇÃO}

Conforme Silva (2003a), nas décadas de 1980 e, principalmente, na de 1990, apesar do SINTTEL-PR ter aderido em nível estadual às políticas de confronto orientadas pela FITTEL e conseqüentemente pela CUT, a sub-sede de Londrina sempre adotou uma política mais branda em relação à Sercomtel.

Por tratar-se de uma empresa controlada pelo município, portanto, desvinculada do extinto Sistema Telebrás, as negociações sempre ocorreram entre o sindicato e a direção da empresa. Em momentos em que essa negociação bilateral resultava em impasses, o sindicato por diversas vezes, recorria à figura do prefeito municipal solicitando dele a intervenção nas negociações em favor dos trabalhadores. Neste sentido, um dos diretores do SINTTEL, em entrevista diz:

Então, na verdade, as negociações com a Sercomtel... quando não acertava entre o sindicato e a diretoria, aí a direção [do sindicato] chegava no prefeito e falava: 'ó, a gente tá pedindo tanto e a empresa só quer dar tanto'. Aí 0 prefeito entrava no meio e ajudava a fazer 0 acordo.

Os telefônicos viveram um grande dilema na década de 1990. A estratégia de fazer oposição propositiva à ofensiva das políticas de privatização da telefonia com o objetivo de obter legitimidade junto à sociedade e junto ao congresso nacional levou-os a legitimar a introdução de novas tecnologias nas empresas do setor. Entretanto, é notório que as inovações tecnológicas constituem-se em um dos 
principais pilares do complexo de reestruturação produtiva sob a mundialização do capital. Dessa forma, os telefônicos brasileiros incentivaram as iniciativas de substituição da base tecnológica do setor.

A posição dos telefônicos justificava-se em razão de defenderem a modernização do sistema de telefonia nacional de forma a colocá-lo em condições de competir com as grandes corporações estrangeiras que passaram a dominar 0 mercado internacional na década de 1990.

Apesar da concordância e até mesmo do incentivo da categoria em relação às mudanças na base técnica, havia em nível nacional, um posicionamento contrário às terceirizações e à introdução dos programas de qualidade total; dois outros importantes pilares da estrutura do modelo de reestruturação predominante em tempos de acumulação flexível.

Os telefônicos perceberam que, diferente do que vinha ocorrendo em outros países, aqui no Brasil, país onde a ofensiva neoliberal ocorreu com pelo menos uma década de atraso, a categoria conseguiria unificar-se e envolver outros setores da sociedade na causa da manutenção da telefonia pública. Por outro lado, acreditavam que teriam força política suficiente para conduzir a reestruturação do setor e 0 acordo com as deliberações tomadas no interior da própria categoria. Um bom exemplo disso foi o Projeto Brasil Telecom³.

Se no país havia oposição dos telefônicos em relação aos programas de qualidade total, na Sercomtel acontecia o inverso. Diante da possibilidade de haver a privatização do Sistema Telebrás, já no início da década de 1990 a empresa se preparava para poder continuar competindo.

Nesse sentido, o próprio SINTTEL-PR, por meio da direção regional de Londrina, incentivava os programas de reestruturação adotados pela empresa.

Acreditamos que esses programas são de fundamental importância. (...) isso será fundamental para tornar o Sercomtel competitivo internacionalmente e por consequiência melhorar as condições de vida dos seus trabalhadores e da comunidade em que está inserido. Qualidade e eficiência é o que todos desejamos, direção da autarquia, funcionários e a diretoria do Sinttel. Não podemos ficar de fora. (BIQUEIRA DE AÇO, n. 16, mar. 96, p. 4).

\footnotetext{
${ }^{3} 0$ Projeto Brasil Telecom foi apresentado ao Governo Brasileiro pela FITTEL e consistia numa proposta de transformação das empresas do Sistema Telebrás em uma grande empresa de telecomunicações estatal que pudesse atuar não só no Brasil, mas também em outros países. Para maiores informações vide Silva (2003a).
} 
Ou seja, enquanto acategoria, em nível nacional, entendia que terceirização, qualidade total, reengenharia, "preceitos do neoliberalismo", constituíam "sinônimo de desemprego" e que era preciso "estruturar uma grande ação de resistência" (BIQUEIRA DE AÇO, n. 2, fev. 96, p. 3), a representação sindical em Londrina destoava o discurso, incentivando a adesão dos trabalhadores aos programas propostos pela empresa.

Tal posicionamento revela que os interesses corporativos dos trabalhadores da Sercomtel foram tratados como prioridade em relação aos interesses do restante da categoria no restante do país. Entretanto, o desencontro de interesses tem uma explicação: como havia a iminência de privatização do Sistema Telebrás e, portanto, o risco de abertura do mercado de telefonia do município para outras empresas, os trabalhadores e o sindicato resolveram adotar uma estratégia corporativa local, visando defender seus interesses imediatos.

Assim, a estratégia adotada foi defender a reestruturação da empresa de modo a torná-la mais ágil e competitiva e por outro lado, garantir a participação dos trabalhadores na divisão dos resultados decorrentes do aumento da produtividade. Isso é o que revela, por exemplo, uma passagem publicada no Boletim Biqueira de Aço (n. 16, mar. 96, p. 4):

0 papel do sindicato é garantir que os funcionários sejam recompensados com uma maior eficiência e lucratividade do Sercomtel. Para isso, uma das nossas maiores bandeiras de luta daqui pra frente deverá ser a Participação nos Resultados.

Observa-se então que mesmo nos períodos de política de confronto da categoria nos níveis nacional e estadual a relação entre o Sinttel e a Sercomtel foi marcada pela proposição e pela participação.

0 sindicato e os trabalhadores não revelam ter apreendido os limites das políticas neocorporativas de cunho propositivo e, em vez de praticar políticas por categoria - o que para Bihr (1998) já representa limitação na medida em que fragmenta as políticas de classe - optaram pela via do sindicalismo de empresa.

Entretanto, nem toda a década de 1990 foi marcada por participação. Quando as estratégias corporativas dos trabalhadores da Sercomtel foram colocadas em "xeque" houve uma forte reação.

0 fato ocorreu justamente quando o primeiro prefeito eleito pelo PT de Londrina, Luiz Eduardo Cheida, acenou para a transformação da autarquia em sociedade anônima. 
Nesse momento, travou-se um conflito político em que se opuseram 0 Sinttel e a administração municipal. 0 Sinttel repudiou a idéia de transformação da autarquia em sociedade anônima. A categoria entendeu que, ao contrário do que estava sendo veiculado oficialmente, ou seja, a modernização da empresa para a atuação além da área original (Londrina, distritos e município de Tamarana), a intenção do prefeito era, na verdade, beneficiar-se do valor da venda das ações para cumprir as promessas de campanha. Em resposta, a categoria mobilizou-se no sentido de resistir às ações da prefeitura (BIQUEIRA DE AÇO, n. 04, mar. 94).

Neste ponto, observa-se que, apesar da categoria ser nacionalmente ligada à CUT (que por sua vez era ligada ao PT) ${ }^{4}$, o fato de o prefeito Cheida ser petista não intimidou uma oposição da categoria à sua política administrativa, o que leva a entender que os interesses corporativos da categoria também predominavam em relação à postura político-partidária que adotavam.

Ao levantar a bandeira da defesa da Sercomtel, empresa fortemente vinculada ao imaginário da população londrinense, o Sinttel conquistou importantes aliados políticos na guerra contra a criação da sociedade anônima, principalmente junto às oposições ao PT.

Em 1992, o sindicato havia conseguido lançar e eleger um vereador, empregado da Sercomtel, que apesar de ser o único pertencente à legenda do prefeito colocou-se em oposição ao executivo, em defesa dos interesses da categoria.

A oposição do Sinttel e de seus aliados políticos à proposta do executivo, resultou numa batalha institucional e judicial que por fim atrasou e inviabilizou 0 projeto do executivo municipal. Assim, o prefeito Cheida transformou a autarquia em sociedade anônima, porém não conseguiu realizar a venda das ações.

A questão foi resolvida na administração posterior (1997), com a venda de 45\% das ações para a empresa que explora os serviços de energia elétrica no Estado, a COPEL 5 .

0 fato dos trabalhadores da Sercomtel e seus representantes sindicais terem aderido, desde o início da década de 1990, às estratégias neocorporativas de

\footnotetext{
${ }^{4}$ Prova disso é a campanha aberta apresentada em diversos números dos boletins da categoria em favor da candidatura Lula a presidência da república, além de apologias a demais políticos do partido.

${ }^{5}$ A COPEL - Companhia Paranaense de Energia é uma empresa de economia mista, controlada pelo Estado do Paraná. Assim, as ações da Sercomtel foram vendidas, mas continuaram sobre controle estatal.
} 
proposição e participação no processo de reestruturação da empresa, em oposição à estratégia adotada pela categoria em nível nacional, soma-se aos elementos que cooperaram para a captura da subjetividade dos trabalhadores por parte da empresa (SILVA, 2006).

Dessa forma, entende-se que o fato dos trabalhadores e do sindicato terem por objetivo estratégico o mesmo que a empresa, ou seja: cooperar com os requisitos demandados pela reestruturação - a exemplo dos programas de qualidade total e o conseqüente envolvimento com os objetivos da Sercomtel, em detrimento de seus interesses de classe ou de categoria - resultou na otimização das expectativas da empresa.

As principais conseqüências da postura dos trabalhadores podem ser avaliadas por meio dos resultados da reestruturação demonstrados por Silva (2003, p.117), dentre os quais o vertiginoso crescimento da empresa em todos os níveis, cujos indicadores a colocam entre as melhores do setor no país.

Em comparação, pode-se avaliar o ocorrido com os próprios trabalhadores, ou seja, a significante redução do número de empregos, conforme mostra o gráfico I e a drástica redução dos níveis salariais em função do corte de benefícios (SILVA, 2003, p. 135-138).

\section{GrÁfico I - EvoluÇÃo do NÚMERO DE EMPREGADOS (1991-2002)}

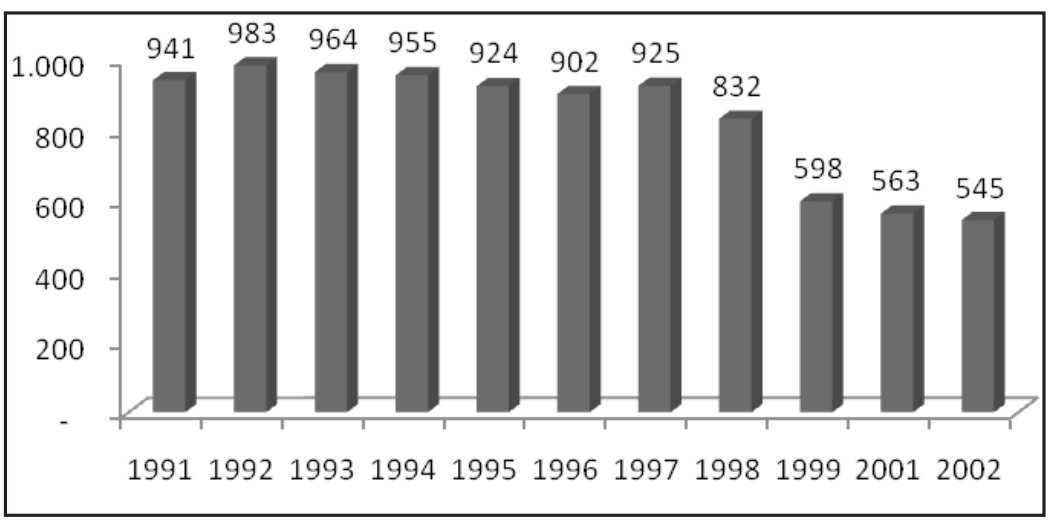

Fonte: Silva (2003, p. 134).

Dados como estes indicam que as estratégias da categoria dos telefônicos, em Londrina na relação com Sercomtel, demonstraram sérios limites quanto à capacidade de conquistar melhorias para as suas condições de reprodução social. 
Na verdade, implicaram em retrocessos se forem comparadas com as conquistas históricas da categoria.

Por outro lado, é preciso reconhecer que a manutenção da Sercomtel enquanto empresa controlada pelo município ainda garante aos trabalhadores efetivos da empresa condições relativamente melhores em relação ao restante da categoria, principalmente no que concerne às condições diárias de trabalho e aos programas sociais mantidos pela empresa a exemplo de plano de saúde, bolsas parciais de incentivo à educação e principalmente a postura que ainda resiste no interior da empresa de não realizar demissões involuntárias sem justa causa (SILVA, 2003).

Em síntese os trabalhadores que restaram na Sercomtel conquistaram com a manutenção da empresa pública o direito de trabalhar da forma mais intensificada e com um nível de comprometimento nunca antes visto na empresa. Para ilustrar a afirmação, cabe a reprodução da fala de um dos técnicos entrevistados: "hoje a gente tem que matar um leão por dia aqui na empresa".

Do ponto de vista das relações políticas com a Administração municipal, é importante observar que com a segunda eleição do PT no município, em 2001, assumiu a presidência da Sercomtel o ex-sindicalista e componentes da chapa Biqueira de Aço que administrara o SINTTEL até 1999, e funcionário da Sercomtel, Francisco Roberto Pereira.

0 ex-sindicalista, que havia defendido os interesses da categoria à frente do sindicato e no legislativo municipal, em 2001, assume a presidência da empresa e passa a negociar em favor dela contra o grupo de oposição sindical que antes denominava de "pelegos".

A ilustração mostra como indivíduos oriundos da classe trabalhadora e que antes se colocavam em oposição a alguns aspectos da reestruturação da empresa, após um longo período de exposição às novas formas de gerenciamento do trabalho pautadas na captura da subjetividade dos trabalhadores, defendem interesses tão reacionários que chegam a chocar com os que antes eram os "pelegos".

\section{CONSIDERAÇõES FINAIS}

0 caso dos telefônicos em nível nacional e o caso específico dos trabalhadores da Sercomtel indicam que as estratégias políticas de fragmentação da classe trabalhadora que predominaram no século XX, primeiro com o confronto, depois 
com o concertacionismo propositivo constituem formas ineficazes de atuação da classe trabalhadora frente à ofensiva do capital sob o contexto de mundialização, na medida em que têm resultado na crescente precarização das condições de trabalho e na hegemonia dos interesses do capital.

Entretanto, apesar de seus limites, no que concerne aos trabalhadores da Sercomtel, ainda que as condições de trabalho, remuneração e os níveis de empregos não sejam hoje, comparáveis aos que se tinha até o ano de 1998, a participação na política sindical durante toda aquela década em certa medida foi importante para manter parte das conquistas de décadas passadas.

É possível dizer que o SINTTEL-PR., enquanto fazia política de confronto, adotou uma estratégia ambígua em relação à Sercomtel e assim cooperou para a manutenção da Sercomtel como empresa pública.

Entretanto, a Sercomtelé a única empresa do setor, no Brasil, que permanece controlada por capital público e continua sendo atrativa para o capital, dado 0 seu potencial tecnológico e de prestação de serviços. Logo, a qualquer momento é possível voltar à baila a questão da privatização da empresa e um sindicalismo forte, atuante politicamente e que consiga envolver os trabalhadores em suas ações, ainda que não esteja vislumbrando a emancipação dos trabalhadores, é fundamental para manter o que não se perdeu no final da década neoliberal.

\section{REFERÊNCIAS}

ALVES, Giovanni. O novo (eprecário) mundo do trabalho. São Paulo: Boitempo/ Fapesp, 2000.

ARAÚJ0, Sílvia M. P. de A ação sindical no contexto político da privatização das telecomunicações no Brasil. Revista Electrônica de Geografía y Ciencias Sociales, Barcelona, vol. I, n. 119 (100), Ago/2002.

BIHR, Alain. Da grande noite à alternativa: a crise do movimento operário europeu. São Paulo: Boitempo, 1998.

BIQUEIRA DE AÇO - Boletim informativo do Sinttel, vários números, 1994-1996.

CUNHA, Sebastião Ferreira da. A reestruturação produtiva na CTBC Telecom e os impactos para a organização de trabalhadores: o caso Sinteel-MG. Dissertação 
de Mestrado, Desenvolvimento Econômico, Instituto de Economia, Universidade Federal de Uberlândia, 2002.

LIMA, José Edmilson de Souza. Biqueira de aço: resistência e pacto do sindicato no setor estatal; os telefônicos do Paraná e as políticas de pacto. Dissertação de Mestrado, Ciência Política, Universidade Federal de Santa Catarina, Florianópolis, 1997.

OLIVEIRA, Marco A. Avanço e limites do sindicalismo brasileiro recente. In: OLIVEIRA, Carlos Alonso (org). O mundo do trabalho: crise e mudança no final de século. Campinas: Scritta/CESIT - UNICAMP, 1994.

SANTOS, Ariovaldo de Oliveira. Trabalho e globalização: a crise do sindicalismo propositivo. Londrina: Práxis, 2001.

SILVA, Givaldo Alves da. Reestruturação produtiva e sindicalismo em empresas de telecomunicações: o caso Sercomtel S/A. Dissertação de Mestrado, Ciências Sociais, Faculdade de Filosofia e Ciência, Universidade Estadual Paulista, Marília, 2003.

A trajetória sindical dos telefônicos na década de 1990. In: BATISTA, Roberto Leme; ARAÚJ0, Renan. Desafios do trabalbo: capital e luta de classes no século XXI. Londrina: Práxis; Massoni: Maringá, p. 243-265, 2003 a.

. Gestão do Trabalho e Subjetividade do Trabalhador: Um Estudo de Caso. Urutágua, Maringá, n. 10, 2006. Disponível em: <http://www.urutagua.uem. br/010/10silva_givaldo.htm >. Acesso em 12/11/2009.

; SANTOS, Verlane Aragão. A inserção da Telefonia Brasileira no quadro de reestruturação mundial das telecomunicações. Redes.com - Revista de Estudios para El desarrolo social de La comunicación, Sevilla, n. 3, p. 377-396, 2006.

VIVAVOZ - Boletim Sinttel/PR, vários números, 2000-2002. 